$\begin{array}{ll}\text { Research Square } & \text { Preprints are preliminary reports that have not undergone peer review. } \\ \text { They should not be considered conclusive, used to inform clinical practice, } \\ \text { or referenced by the media as validated information. }\end{array}$

\title{
The duration of estrogen treatment before progesterone application does not affect neonatal and perinatal outcomes in single frozen blastocyst transfer cycles
}

Mingze Du

Third Affiliated Hospital of Zhengzhou University

Junwei Zhang

Third Affiliated Hospital of Zhengzhou University

Xiaona Yu

Third Affiliated Hospital of Zhengzhou University

Jiaheng $\mathbf{L i}$

Third Affiliated Hospital of Zhengzhou University

Xinmi Liu

Third Affiliated Hospital of Zhengzhou University

Lijun Sun

Third Affiliated Hospital of Zhengzhou University

Xingling Wang

Third Affiliated Hospital of Zhengzhou University

Yichun Guan ( $\sim$ guanyichun1616@126.com )

The Third Affiliated Hospital of Zhengzhou University

\section{Research}

Keywords: duration of estrogen, frozen blastocyst transfer, neonatal outcomes, perinatal outcomes

Posted Date: September 8th, 2021

DOI: https://doi.org/10.21203/rs.3.rs-877891/v1

License: () (i) This work is licensed under a Creative Commons Attribution 4.0 International License. Read Full License 


\section{Abstract}

Background: The number of frozen embryo transfer (FET) cycles has substantially increased in the past decade. Preparing the endometrium in artificial cycles is widely used in clinical practice. Therefore, how to optimize this program, improve the clinical outcome and ensure the safety of the perinatal period is the focus of our attention. The purpose of this study was to explore whether the duration of estrogen treatment before progesterone application affects neonatal and perinatal outcomes in single frozen blastocyst transfer cycles.

Methods: It was a retrospective cohort study. Patients receiving single frozen blastocyst transfer and delivering a single live birth between January 2015 and December 2019 were included. Primary outcome was small for gestational age (SGA). Secondary outcomes were neonatal birthweight, gestational weeks at delivery, preterm birth, low birth weight (LBW), macrosomia, large for gestational age (LGA), neonatal malformation and rate of pregnancy-related complications.

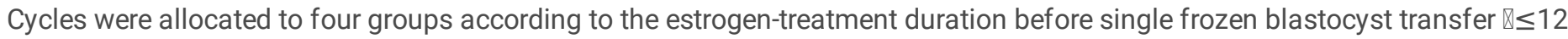
days $(n=306), \otimes 13-15$ days $(n=620), \otimes 16-18$ days $(n=471), \otimes \geq 19$ days $(n=275)$.

Results: In total, 1672 cycles were analyzed. Cycles were allocated to four groups according to the estrogen-treatment duration

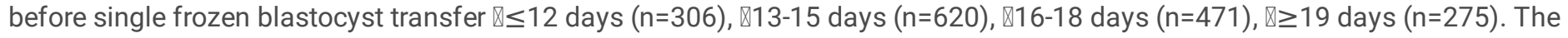
rates of SGA among the four groups were 7.8\% (24/306), 4.8\% (30/620), 5.7\% (27/471), and 7.6\% (21/275), with no statistical significance $(P=0.20)$. Other neonatal outcomes, including mean neonatal birth weight, gestational weeks at delivery, preterm birth rate, LBW, macrosomia, LGA and neonatal malformation, were comparable among the groups $(P=0.38, P=0.16, P=0.20, P=0.58$, $P=0.20, P=0.34, P=0.96)$. The rate of pregnancy-related complications was similar among the groups. Multiple logistics regression showed that the duration of estrogen treatment did not affect the rate of singleton SGA (13-15 days, $\mathrm{AOR}=1.37,95 \% \mathrm{Cl}=0.70-2.70$, $\mathrm{P}=0.36 ; 16-18$ days, $\mathrm{AOR}=0.74,95 \% \mathrm{Cl}=0.40-1.36, \mathrm{P}=0.34 ; \geq 19$ days, $\mathrm{AOR}=0.81,95 \% \mathrm{Cl}=0.44-1.49, \mathrm{P}=0.50)$.

Conclusion: The estrogen-treatment duration before progesterone application does not affect neonatal and perinatal outcomes in single frozen blastocyst transfer cycles.

\section{Introduction}

In the past decade, the number of frozen embryo transfer (FET) cycles has substantially increased. Currently, up to half of embryos are cryopreserved, and FET is performed[1]. This trend may be related to the improvement and development of vitrification technology and a rapid rise in single embryo transfer (ET), combined with the development of preimplantation genetic tests (PGTs) [2-4]. In addition, current studies have shown that FET can reduce in vitro fertilization (IVF) complications, such as ovarian hyperstimulation syndrome, increase the cumulative live birth rate, and improve perinatal and offspring outcomes[5-7]. How to improve the live birth rate of FET cycles and ensure the safety of mothers and offspring is the focus of our research and attention. Ensuring the synchronization of embryo and endometrial development is a key step in obtaining pregnancy. However, the optimal endometrial preparation protocols for FET are still a topic of constant debate[8-10]. The artificial cycle is mainly suitable for patients with abnormal ovulation or nonovulation. The application of exogenous estrogen and progesterone can promote the development of the endometrium and promote the synchronization of the development of the endometrium and the embryo. Preparing the endometrium in artificial cycles, which can flexibly arrange the transplantation time and reduce the number of monitoring procedures, is widely used in clinical practice[1]. Therefore, how to optimize this program, improve the clinical outcome and ensure the safety of the perinatal period is the focus of our attention. At present, there are studies exploring the optimal duration of estrogen treatment before progesterone application; however, most studies focus on the pregnancy rate or live birth rate [11-15]. To the best of our knowledge, only two studies have analyzed the relationship between the duration of estrogen treatment and offspring safety $[13,15]$. However, the conclusions of the two studies are not consistent. Due to the differences in the included population and groupings, it is necessary to further analyze the effect of estrogen use time on neonatal and perinatal outcomes. Therefore, the purpose of this study was to analyze the effect of the duration of estrogen treatment before progesterone application on the safety of offspring and perinatal outcomes. To reduce the influence of confounding factors, this study only included the offspring of single blastocyst transfer and delivery of a single live birth.

\section{Materials And Methods}




\section{Study design and population}

This was a retrospective cohort study conducted in the reproductive center of the Third Affiliated Hospital of Zhengzhou University. Permission to conduct this study was obtained from the Ethics Committee of the Third Affiliated Hospital of Zhengzhou University. The outcomes of patients receiving single frozen blastocyst transfer and delivering a single live birth between January 2015 and December 2019 were included for potential analysis. All included patients had the endometrium prepared for ET through artificial cycles. Cycles with more than one blastocyst transfer were excluded from the analysis. We excluded cycles with oocyte donation, PGT and incomplete data. In addition, studies have shown that thin endometrium thickness (EMT) may have an impact on offspring weight and perinatal outcomes [16-19]. To reduce the influence of thin EMT, cycles with EMT $\leq 7 \mathrm{~mm}$ on the 10 days from the initiation of estrogen administration were excluded from analysis.

\section{Endometrial preparation and ET}

The controlled ovarian stimulation protocols and IVF/ICSI process have been described in our previous studies[5, 20, 21]. In the present study, all patients underwent artificial cycles for FET. Vaginal ultrasound examination was performed on the $2 \mathrm{nd} / 3 \mathrm{rd}$ day of the menstrual cycle, 2-3 mg of estradiol valerate was taken orally three times daily (Bayer Co. Germany), and vaginal ultrasound examination was performed 7 days later. The drug dose was adjusted according to the thickness of the endometrium (up to $9 \mathrm{mg}$ per day). The duration of estrogen treatment continued for at least 10 days. If conditions were appropriate (EMT $>7 \mathrm{~mm}$, serum estrogen level $\geq 150 \mathrm{pg} / \mathrm{ml}$ and serum progesterone $<1.5 \mathrm{ng} / \mathrm{ml}$ ) and the patient's schedule was feasible, the progesterone exposure day was formulated. Routine corpus luteum support, namely, oral dydrogesterone (2 times daily, $10 \mathrm{mg}$ once) (Abbott Co. America) and intravaginal administration of $90 \mathrm{mg}$ of a progesterone sustained-release vaginal gel (Merck Co. Germany), was given. Five days after endometrial development with corpus luteum support, single blastocyst transplantation was carried out by abdominal ultrasound. Corpus luteum support was performed at least until 55 days after transplantation if pregnancy occurred.

According to the duration of estrogen treatment before single frozen blastocyst transfer, we divided the cycles into four groups: $₫ \leq 12$ days, $\mathbb{\nabla}$ 13-15 days, $\otimes 16-18$ days, and $\varangle \geq 19$ days. The ' $\leq 12$ days group' was considered the reference group. The grouping was mainly based on the interquartile range of estrogen treatment.

\section{Outcome measures and definition}

The primary concern of this study was smallness for gestational age (SGA), which was defined as a birth weight less than the 10th centile for gestational age[22]. The weight criteria refer to the weight of Chinese newborns[23].

The secondary outcomes included neonatal birthweight, gestational weeks at delivery, preterm birth (defined as a birth that takes place after 28 weeks and before 37 completed weeks of gestational age), low birth weight (LBW, defined as a neonatal birth weight less than $2500 \mathrm{~g}$ )[22], macrosomia (defined as a neonatal birth weight more than $4000 \mathrm{~g}$ ), largeness for gestational age (LGA, defined as a birth weight greater than the 90th centile of the sex-specific birth weight[22], with sex-specific birth weight referring to the weight of Chinese newborns[23]) and neonatal malformation. We also analyzed the rate of pregnancy-related complications among groups, including hypertensive states of pregnancy, gestational diabetes mellitus, placenta previa, placental abruption and premature rupture.

\section{Statistical analysis}

All the data in this article were obtained from the electronic medical record system of the reproductive center of the Third Affiliated Hospital of Zhengzhou University.

The one-sample Kolmogorov-Smirnov test was used to check for normality of continuous variables. Continuous variables with abnormal distributions are expressed as the median (P25, P75), and the between-group differences were assessed by the Wilcoxon rank sum test. Categorical variables are represented as the number of cases ( $n$ ) and percentage (\%). The means from chi-square analyses were used to assess the differences between groups with Fisher's exact test when necessary. For the main concern of this study, namely, SGA, multiple logistic regression were used to adjust for the baseline characteristics. Adjusted odds ratios (AORs) with $95 \%$ confidence intervals $(\mathrm{Cls})$ were calculated. $\mathrm{P}<0.05$ was considered to be statistically significant.

All statistical management and analyses were performed using SPSS software, version 22.0. 


\section{Results}

\section{Study population}

The detailed inclusion and exclusion criteria are shown in Fig. 1. A total of 20,345 FET cycles were performed from January 2015 to December 2019. Cycles with cleavage ET $(n=9512)$, more than one blastocyst transfer $(n=365)$, oocyte donation $(n=139)$, PGT $(n=$ $224)$ and incomplete important data $(n=79)$ were excluded. We excluded natural cycles $(n=3265)$, GnRH-agonist + artificial cycles $(n=762)$ and ovarian stimulation cycles $(n=1980)$. Cycles with EMT $\leq 7.5 \mathrm{~mm}$ were excluded $(n=162)$. A total of 1672 cycles with singleton live births from single blastocyst transfer were included for analysis.

Cycles were allocated to four groups according to the duration of estrogen treatment before single frozen blastocyst transfer $\varangle \leq 12$ days $(n=306)$, $\nabla 13-15$ days $(n=620), \varangle 16-18$ days $(n=471), \varangle \geq 19$ days $(n=275)$.

Baseline characteristics

The details of the baseline and cycle characteristics among the groups are described in Table 1. The endometrial thickness was different among groups on the first day of progesterone administration ( $\leq 12$ days, $9.5(8.7,10.5) ; 13-15$ days, $9.0(8.3,10.0)$; $16-18$ days, $8.5(8.0,9.3) ; \geq 19$ days, $8.1(7.5,9.0), P<0.001)$. Apart from this, there were no significant differences in other basic characteristics, including maternal age at oocyte retrieval, paternal age, body mass index (BMI), duration of infertility, type of infertility, gravidity, parity, causes of infertility, basal serum $\mathrm{FSH}$ level, $\mathrm{AMH}$, basal antral follicle count, serum estradiol on the trigger day of the controlled ovarian hyperstimulation $(\mathrm{COH})$ cycles, the rate of IVF and the rate of good-quality blastocyst transfer (a goodquality blastocyst is defined as a $\mathrm{B} 3-\mathrm{B} 4$ or $\mathrm{B} 5$ embryo $\geq \mathrm{BB}(\mathrm{AA}, \mathrm{AB}, \mathrm{BA}, \mathrm{BB})$ ) according to the grading scale proposed by Gardner[24]). 
Table 1

Baseline and cycle characteristics among groups.

\begin{tabular}{|c|c|c|c|c|c|}
\hline \multirow[t]{2}{*}{ Parameters } & \multicolumn{4}{|c|}{ Duration of estrogen treatment before embryo transfer (days) } & \multirow{2}{*}{$\begin{array}{l}P \\
\text { value }\end{array}$} \\
\hline & $\leq 12(n=306)$ & $13-15(n=620)$ & $16-18(n=471)$ & $\geq 19(n=275)$ & \\
\hline $\begin{array}{l}\text { Maternal age } \\
\text { at oocytes } \\
\text { retrieved(year) }\end{array}$ & $30.0(28.0,33.0)$ & $30.0(27.0,33.0)$ & $30.0(28.0,32.0)$ & $29.0(27.0,32.0)$ & 0.06 \\
\hline $\begin{array}{l}\text { Paternal } \\
\text { age(year) }\end{array}$ & $31.0(28.0,34.0)$ & $30.0(28.0,34.0)$ & $30.0(28.0,33.0)$ & $30.0(27.0,34.0)$ & 0.17 \\
\hline $\mathrm{BMI}\left(\mathrm{kg} / \mathrm{m}^{2}\right)$ & $24.1(21.7,26.2)$ & $23.6(21.5,25.8)$ & $24.1(22.0,26.1)$ & $23.4(21.4,25.4)$ & 0.07 \\
\hline $\begin{array}{l}\text { Duration of } \\
\text { infertility(year) }\end{array}$ & $3.0(1.0,5.0)$ & $3.0(1.0,5.0)$ & $3.0(1.0,4.0)$ & $3.0(1.0,4.0)$ & 0.07 \\
\hline $\begin{array}{l}\text { Type of } \\
\text { infertility (\%) }\end{array}$ & & & & & 0.13 \\
\hline $\begin{array}{l}\text { Primary } \\
\text { infertility }\end{array}$ & $52.0(159 / 306)$ & $45.6(283 / 620)$ & $46.5(219 / 471)$ & $42.5(117 / 275)$ & \\
\hline $\begin{array}{l}\text { Secondary } \\
\text { infertility }\end{array}$ & $48.0(147 / 306)$ & $54.4(337 / 620)$ & $53.5(252 / 471)$ & $57.5(158 / 275)$ & \\
\hline Gravidity & $0(0,1)$ & $1(0,2)$ & $1(0,2)$ & $1(0,2)$ & 0.19 \\
\hline Parity & $0(0,1)$ & $0(0,1)$ & $0(0,1) 0$ & $0(0,1)$ & 0.61 \\
\hline $\begin{array}{l}\text { Causes of } \\
\text { infertility (\%) }\end{array}$ & & & & & 0.06 \\
\hline Tubal factor & $28.4(87 / 306)$ & $28.5(177 / 620)$ & $31.0(146 / 471)$ & $37.5(103 / 275)$ & \\
\hline Male factor & $20.3(62 / 306)$ & $26.0(161 / 620)$ & $25.3(119 / 471)$ & $20.4(56 / 275)$ & \\
\hline $\begin{array}{l}\text { Male + female } \\
\text { factors }\end{array}$ & $21.9(67 / 306)$ & $16.9(105 / 620)$ & $16.8(79 / 471)$ & $18.9(52 / 275)$ & \\
\hline Others & $29.4(90 / 306)$ & $28.5(177 / 620)$ & $27.0(127 / 471)$ & $23.3(64 / 275)$ & \\
\hline $\begin{array}{l}\text { Basal serum } \\
\text { FSH } \\
\text { level(IU/L) }\end{array}$ & $6.2(4.9,7.4)$ & $6.1(4.7,7.2)$ & $6.0(4.7,7.4)$ & $6.4(5.0,7.3)$ & 0.31 \\
\hline $\mathrm{AMH}(\mathrm{ng} / \mathrm{ml})$ & $4.6(2.1,6.6)$ & $4.8(2.9,6.2)$ & $4.9(2.1,6.8)$ & $5.0(2.4,6.3)$ & 0.11 \\
\hline $\begin{array}{l}\text { Basal antral } \\
\text { follicle count }\end{array}$ & $20.0(13.0,24.0)$ & $20.0(15.0,24.0)$ & $22.0(15.0,24.0)$ & $22.0(17.0,24.0)$ & 0.15 \\
\hline $\begin{array}{l}\text { Serum } \\
\text { estradiol on } \\
\text { the trigger day } \\
\text { of the } \mathrm{COH} \\
\text { cycles }(\mathrm{pg} / \mathrm{ml})\end{array}$ & $3033.0(1866.5,4532.5)$ & $3077.9(2197.5,4607.5)$ & $3191.5(2123.5,4637.3)$ & $3090.2(2091.5,4167.5)$ & 0.39 \\
\hline $\begin{array}{l}\text { Fertilization } \\
\text { method (\%) }\end{array}$ & & & & & 0.50 \\
\hline IVF & $68.6(210 / 306)$ & $65.0(403 / 620)$ & $68.4(322 / 471)$ & $69.1(190 / 275)$ & \\
\hline ICSI & $31.4(96 / 306)$ & $35.0(217 / 620)$ & $31.6(149 / 471)$ & $30.9(85 / 275)$ & \\
\hline $\begin{array}{l}\text { Endometrial } \\
\text { thickness on } \\
\text { the first day of } \\
\text { progesterone } \\
\text { administration } \\
(\mathrm{mm})\end{array}$ & $9.5(8.7,10.5)$ & $9.0(8.3,10.0)$ & $8.5(8.0,9.3)$ & 8.1(7.5,9.0) & $<.001$ \\
\hline
\end{tabular}




\begin{tabular}{|c|c|c|c|c|c|}
\hline \multirow[t]{2}{*}{ Parameters } & \multicolumn{4}{|c|}{ Duration of estrogen treatment before embryo transfer (days) } & \multirow{2}{*}{$\begin{array}{l}P \\
\text { value }\end{array}$} \\
\hline & $\leq 12(n=306)$ & $13-15(n=620)$ & $16-18(n=471)$ & $\geq 19(n=275)$ & \\
\hline $\begin{array}{l}\text { The rate of } \\
\text { good-quality } \\
\text { blastocyst } \\
\text { transfer* }\end{array}$ & $63.1(193 / 306)$ & $63.9(396 / 620)$ & $67.9(320 / 471)$ & $61.5(169 / 275)$ & 0.27 \\
\hline
\end{tabular}

Table 2

Comparison of neonatal and perinatal outcomes among groups.

\begin{tabular}{|c|c|c|c|c|c|}
\hline & \multicolumn{4}{|c|}{ Duration of estrogen treatment before embryo transfer (days) } & \multirow{2}{*}{$\begin{array}{l}P \\
\text { value }\end{array}$} \\
\hline & $\leq 12(n=306)$ & $13-15(n=620)$ & $16-18(n=471)$ & $\geq 19(n=275)$ & \\
\hline \multicolumn{6}{|l|}{ Neonatal outcomes } \\
\hline Neonatal birth weight (g) & $3500(3200,3850)$ & $3500(3200,3895)$ & $3400(3100,3800)$ & $3500(3100,3800)$ & 0.38 \\
\hline Neonatal sex (\%) & & & & & 0.45 \\
\hline Male & $57.5(176 / 306)$ & $55.6(345 / 620)$ & $57.1(269 / 471)$ & $51.6(142 / 275)$ & \\
\hline Female & $42.5(130 / 306)$ & $44.4(275 / 620)$ & $42.9(202 / 471)$ & $48.4(133 / 275)$ & \\
\hline Gestational weeks at delivery (week) & $39(38,40)$ & $39(38,40)$ & $39(38,40)$ & $39(38,40)$ & 0.16 \\
\hline Preterm birth (\%) & $6.2(19 / 306)$ & $6.3(39 / 620)$ & $8.3(39 / 471)$ & $4.4(12 / 275)$ & 0.20 \\
\hline Low birth weight (\%) & $5.6(17 / 306)$ & $4.8(30 / 620)$ & $6.8(32 / 471)$ & $5.5(15 / 275)$ & 0.58 \\
\hline Small-for-gestational age (\%) & $7.8(24 / 306)$ & $4.8(30 / 620)$ & $5.7(27 / 471)$ & $7.6(21 / 275)$ & 0.20 \\
\hline Macrosomia (\%) & $14.4(44 / 306)$ & $18.7(116 / 620)$ & $16.6(78 / 471)$ & $13.8(38 / 275)$ & 0.20 \\
\hline Large-for-gestational age (\%) & $22.9(70 / 306)$ & $26.3(163 / 620)$ & $22.7(107 / 471)$ & $21.5(59 / 275)$ & 0.34 \\
\hline Neonatal malformation (\%) & $0.7(2 / 306)$ & $0.5(3 / 620)$ & $0.4(2 / 471)$ & $0.4(1 / 275)$ & 0.96 \\
\hline \multicolumn{6}{|l|}{ Pregnancy-related complications } \\
\hline $\begin{array}{l}\text { Hypertensive states of pregnancy } \\
(\%)\end{array}$ & $5.6(17 / 306)$ & $6.1(38 / 620)$ & $8.7(41 / 471)$ & $8.0(22 / 275)$ & 0.24 \\
\hline Gestational diabetes mellitus (\%) & $3.9(12 / 306)$ & $8.1(50 / 620)$ & $7.0(33 / 471)$ & $5.5(15 / 275)$ & 0.09 \\
\hline Placenta previa (\%) & $1.3(4 / 306)$ & $1.0(6 / 620)$ & $0.4(2 / 471)$ & $1.1(3 / 275)$ & 0.54 \\
\hline Placental abruption (\%) & $0.7(2 / 306)$ & $1.0(6 / 620)$ & $0.2(1 / 471)$ & $0.7(1 / 275)$ & 0.49 \\
\hline Premature rupture (\%) & $2.9(9 / 306)$ & $3.1(19 / 620)$ & $2.5(12 / 471)$ & $1.1(3 / 275)$ & 0.37 \\
\hline
\end{tabular}

\section{Neonatal And Perinatal Outcomes}

The main outcome measure was the rate of SGA among the four groups, which was 7.8\% (24/306), 4.8\% (30/620), 5.7\% (27/471), and $7.6 \%(21 / 275)$, with no statistical significance $(P=0.20)$. The mean neonatal birth weight was comparable among groups $(\leq 12$ days, 3500 (3200, 3850); 13-15 days, 3500 (3200, 3895); 16-18 days, 3400 (3100, 3800); $\geq 19$ days, 3500 (3100, 3800), $P=0.38)$. The neonatal sex ratio $(P=0.45)$ and gestational weeks at delivery were similar between the groups $(P=0.16)$. The preterm birth rates among the four groups were $6.2 \%$ (19/306), 6.3\% (39/620), 8.3\% (39/471), and 4.4\% (12/275), with no statistical significance $(P=0.20)$. The rates of $L B W$, macrosomia, $L G A$ and neonatal malformation were comparable among the groups $(P=0.58, P=0.20, P$ $=0.34, P=0.96)$. Pregnancy-related complications, including hypertensive states of pregnancy, gestational diabetes mellitus, 
placenta previa, placental abruption and premature rupture, were similar among the groups $(P=0.24, P=0.09, P=0.54, P=0.49, P=$ 0.37).

Regarding SGA, to adjust for the influence of confounding factors, we conducted a multiple logistic regression analysis. The included factors were maternal age (continuous variable), body mass index (continuous variable), duration of infertility (continuous variable), type of infertility (primary/secondary infertility), infertility diagnosis(tubal/male/both/others), basal antral follicle count (continuous variable), basal serum FSH level (continuous variable), gravidity (continuous variable), parity (continuous variable), fertilization method (IVF/ICSI), endometrial thickness on the first day of progesterone administration (continuous variable) and blastocyst quality (good-quality/non-good-quality).

After adjustments for confounding factors, taking ' $\leq 12$ days group' as the reference group, the duration of estrogen treatment did not affect the rate of singleton SGA (13-15 days, AOR $=1.37,95 \% \mathrm{Cl}=0.70-2.70, \mathrm{P}=0.36 ; 16-18$ days, $\mathrm{AOR}=0.74 \otimes 95 \% \mathrm{Cl}=0.40-$ $1.36, \mathrm{P}=0.34 ; \geq 19$ days, $\mathrm{AOR}=0.81,95 \% \mathrm{Cl}=0.44-1.49, \mathrm{P}=0.50)$. The results of logistic regression analysis indicated that maternal BMI was a significant predictor for $S G A(A O R=0.93,95 \% \mathrm{Cl}=0.88-0.99, \mathrm{P}=0.04)$. The specific AOR values with their $95 \%$ Cls are presented in Table 3.

Table 3

Multivariable logistic regression analysis to account for confounding variables for SGA.

\begin{tabular}{|c|c|c|}
\hline & Adjusted OR (95\%Cl) & $P$-value \\
\hline Maternal age(year) & $1.03(0.97-1.09)$ & 0.36 \\
\hline Body mass index $\left(\mathrm{kg} / \mathrm{m}^{2}\right)$ & $0.93(0.88-0.99)$ & 0.04 \\
\hline Duration of Infertility (year) & $0.92(0.83-1.01)$ & 0.09 \\
\hline Type of infertility(Primary/ Secondary infertility) & $0.69(0.38-1.24)$ & 0.21 \\
\hline Infertility diagnosis(Tubal/ Male/ both/Others) & $1.05(0.88-1.26)$ & 0.57 \\
\hline Basal antral follicle count & $0.99(0.97-1.03)$ & 0.93 \\
\hline Basal serum FSH level(IU/L) & $1.03(0.95-1.11)$ & 0.43 \\
\hline Gravidity & $0.82(0.62-1.10)$ & 0.18 \\
\hline Parity & $1.32(0.90-1.96)$ & 0.16 \\
\hline Fertilization method(IVF/ICSI) & $1.03(0.94-1.12)$ & 0.57 \\
\hline Endometrial thickness on the first day of progesterone administration (mm) & $0.85(0.72-1.01)$ & 0.07 \\
\hline Blastocyst quality(good-quality*/ Non-good-quality) & $1.09(0.70-1.71)$ & 0.70 \\
\hline Duration of estrogen treatment (days) & & 0.67 \\
\hline$\leq 12$ (reference) & 1 & \\
\hline $13-15$ & $1.37(0.70-2.70)$ & 0.36 \\
\hline $16-18$ & $0.74(0.40-1.36)$ & 0.34 \\
\hline$\geq 19$ & $0.81(0.44-1.49)$ & 0.50 \\
\hline
\end{tabular}

\section{Discussion}

The purpose of this study was to analyze whether the duration of estrogen treatment before progesterone application affects neonatal and perinatal outcomes in single frozen blastocyst transfer cycles. Through our single-center retrospective cohort study, our results show that the duration of estrogen treatment does not affect offspring and perinatal outcomes. 
Globally, the incidence of infertility is as high as $10 \%$, and IVF is an important method of infertility treatment[25, 26]. However, adverse pregnancy and perinatal outcomes, such as SGA, LBW, preterm birth, pregnancy-induced hypertension and gestational diabetes, were increased in IVF/ICSI cycles, even for singleton births[27, 28]. However, the exact biological mechanism leading to adverse perinatal outcomes is unclear. Some studies have shown that infertility disease itself is the main reason for the poor perinatal outcome of assisted reproductive technology (ART) singleton offspring[29]. However, an increasing number of studies have shown that the process of ART, such as the exposure to superphysiological doses of estrogen, may have an adverse effect on perinatal outcomes[20,30,31]. The mechanism may be that superphysiological doses of estrogen may affect the development of the endometrium rather than the development and quality of the embryo[32,33]. In the artificial cycle of FET, exogenous estrogen is supplemented to cause endometrial hyperplasia while inhibiting the development of dominant follicles. When the endometrium is suitable, exogenous progesterone is supplemented to promote the synchronous development of the endometrium and the embryo. It is not clear whether prolonging the use of estrogen would affect offspring and perinatal outcomes. To the best of our knowledge, only two studies have analyzed the relationship between the duration of estrogen treatment and neonatal and perinatal outcomes. Bourdon $\mathrm{M}$ et al.[13] reported that the mean birth weight and Z-scores were significantly lower for the '36-48 days' group than for the ' $\leq 21$ days' group ( $3042 \pm 801.2 \mathrm{~g}$ and $-0.44 \pm 1.50 \mathrm{vs.} 3362 \pm 602.9 \mathrm{~g}$ and $0.10 \pm 0.94$, respectively). Another study included only single, vitrified-warmed, euploid blastocysts, and the results showed that variation in the duration of estradiol supplementation before progesterone initiation did not impact frozen, euploid blastocyst transfer outcomes. The duration of estrogen administration was inversely correlated with gestational age at delivery, but this did not translate into an increase in preterm delivery[15].

To date, our research is the largest retrospective cohort study to analyze the relationship between the duration of estrogen treatment before progesterone application and neonatal outcomes. This is the first study to analyze the relationship of this duration to pregnancy complications, including hypertensive states of pregnancy, gestational diabetes mellitus, placenta previa, placental abruption and premature rupture. Through analysis, different estrogen use times had no significant effect on offspring or perinatal outcomes. Moreover, because the neonatal and perinatal outcomes of embryo and blastocyst transfer may be different[34], this study included only single blastocyst transfer and delivery singleton birth, thereby reducing the influence of confounding factors. However, this study also has certain limitations. First, it suffers from the limitation of a retrospective cohort, although we used strict inclusion and exclusion criteria and multiple logistic regression to correct for the influence of confounding factors. Second, regarding the duration of estrogen use, the time range of hormone use at our center is 10-30 days, most of the treatment durations are 13-18 days (25\%-75\%), and only 275 cases have been treated more than 19 days; this estrogen use time is shorter than that in Bourdon M's[13] study, and his research shows that a duration of estrogen treatment greater than 35 days may have an impact on the outcome of offspring mean birth weight. However, in our center, there are almost no transplantation cycles with an estrogen application time greater than 35 days. According to our current data in our reproductive center, the duration of estrogen therapy does not affect offspring and perinatal outcomes, but it is uncertain whether extending the estrogen application time will affect the outcome. Consequently, further analysis of the safety of the estrogen-treatment duration before progesterone application is needed for a well-designed, prospective, and large-scale cohort study.

\section{Conclusion}

In conclusion, the duration of estrogen treatment before progesterone application does not affect neonatal and perinatal outcomes in single frozen blastocyst transfer cycles. For patients and clinicians, the transplant time can be flexibly arranged for FET in artificial cycles. However, further randomized controlled studies with large samples are needed.

\section{Abbreviations}

ART

assisted reproductive technology

$\mathrm{BMI}$

body mass index

IVF

in vitro fertilization

ICSI

intracytoplasmic sperm injection 
FSH

follicle-stimulating hormone

FET

frozen embryo transfer

hCG

human chorionic gonadotropin

GnRH

gonadotrophin-releasing hormone

SGA

small for gestational age

LGA

large for gestational age

LBW

low birth weight

OR

odds ratio

$\mathrm{Cl}$

confidence interval

\section{Declarations}

\section{Ethics approval and consent to participate}

This study was approved by the ethics committee of The Third Affiliated Hospital of Zhengzhou University

\section{Consent for publication}

Not applicable.

\section{Availability of data and material}

All data are included in this article.

\section{Competing interests}

The authors declare that they have no competing interests.

\section{Funding}

We did not receive any funding for this study.

\section{Authors' contributions}

GYC designed the study. DMZ and ZJW selected the population to be included and excluded. ZJW and LXM were involved in the data extraction and analysis. YXN and LJH reviewed the data. DMZ was involved in drafting this article. WXL reviewed and revised this manuscript. All authors have approved the final version of the manuscript.

\section{Acknowledgments}

The authors acknowledge the patients who participated in the study and thank staff members of the Reproductive Center of the Third Affiliated Hospital of Zhengzhou University for their expert assistance with data collection and follow-up. We also thank American Journal Experts for their professional manuscript editing service.

\section{References}


1. Groenewoud ER, Cohlen BJ, Macklon NS. Programming the endometrium for deferred transfer of cryopreserved embryos: hormone replacement versus modified natural cycles. Fertil Steril. 2018;109:768-74.

2. Pereira N, Rosenwaks Z. A fresh(er) perspective on frozen embryo transfers. Fertil Steril. 2016;106:257-8.

3. Gliozheni O, Calhaz-Jorge C, De Geyter C, Kupka MS, de Mouzon J, Erb K, Mocanu E, Motrenko T, Scaravelli G, Wyns C, et al. Assisted reproductive technology in Europe, 2013: results generated from European registers by ESHRE. Hum Reprod. 2017;32:1957-73.

4. Rienzi L, Gracia C, Maggiulli R, LaBarbera AR, Kaser DJ, Ubaldi FM, Vanderpoel S, Racowsky C. Oocyte, embryo and blastocyst cryopreservation in ART: systematic review and meta-analysis comparing slow-freezing versus vitrification to produce evidence for the development of global guidance. Hum Reprod Update. 2017;23:139-55.

5. Zhang J, Du M, Li Z, Wang L, Hu J, Zhao B, Feng Y, Chen X, Sun L. Fresh versus frozen embryo transfer for full-term singleton birth: a retrospective cohort study. J Ovarian Res. 2018;11:59.

6. Chen ZJ, Shi Y, Sun Y, Zhang B, Liang X, Cao Y, Yang J, Liu J, Wei D, Weng N, et al. Fresh versus Frozen Embryos for Infertility in the Polycystic Ovary Syndrome. N Engl J Med. 2016;375:523-33.

7. Shi Y, Sun Y, Hao C, Zhang H, Wei D, Zhang Y, Zhu Y, Deng X, Qi X, Li H, et al. Transfer of Fresh versus Frozen Embryos in Ovulatory Women. N Engl J Med. 2018;378:126-36.

8. Ghobara T, Gelbaya TA, Ayeleke RO. Cycle regimens for frozen-thawed embryo transfer. Cochrane Database Syst Rev. 2017;7:CD003414.

9. Glujovsky D, Pesce R, Sueldo C, Quinteiro Retamar AM, Hart RJ, Ciapponi A. Endometrial preparation for women undergoing embryo transfer with frozen embryos or embryos derived from donor oocytes. Cochrane Database Syst Rev. 2020;10:Cd006359.

10. Ghobara T, Vandekerckhove P. Cycle regimens for frozen-thawed embryo transfer. Cochrane Database Syst Rev 2008:Cd003414.

11. Younis JS, Mordel N, Lewin A, Simon A, Schenker JG, Laufer N. Artificial endometrial preparation for oocyte donation: the effect of estrogen stimulation on clinical outcome. J Assist Reprod Genet. 1992;9:222-7.

12. Borini A, Dal Prato L, Bianchi L, Violini F, Cattoli M, Flamigni C. Effect of duration of estradiol replacement on the outcome of oocyte donation. J Assist Reprod Genet. 2001;18:185-90.

13. Bourdon M, Santulli P, Kefelian F, Vienet-Legue L, Maignien C, Pocate-Cheriet K, de Mouzon J, Marcellin L, Chapron C. Prolonged estrogen (E2) treatment prior to frozen-blastocyst transfer decreases the live birth rate. Hum Reprod. 2018;33:905-13.

14. Yaron Y, Amit A, Mani A, Yovel I, Kogosowski A, Peyser MR, David MP, Lessing JB. Uterine preparation with estrogen for oocyte donation: assessing the effect of treatment duration on pregnancy rates. Fertil Steril. 1995;63:1284-6.

15. Sekhon L, Feuerstein J, Pan S, Overbey J, Lee JA, Briton-Jones C, Flisser E, Stein DE, Mukherjee T, Grunfeld L, et al. Endometrial preparation before the transfer of single, vitrified-warmed, euploid blastocysts: does the duration of estradiol treatment influence clinical outcome? Fertil Steril. 2019;111:1177-85.e1173.

16. Mouhayar Y, Franasiak JM, Sharara Fl. Obstetrical complications of thin endometrium in assisted reproductive technologies: a systematic review. J Assist Reprod Genet. 2019;36:607-11.

17. Moffat R, Beutler S, Schotzau A, De Geyter M, De Geyter C. Endometrial thickness influences neonatal birth weight in pregnancies with obstetric complications achieved after fresh IVF-ICSI cycles. Arch Gynecol Obstet. 2017;296:115-22.

18. Guo Z, Xu X, Zhang L, Zhang L, Yan L, Ma J. Endometrial thickness is associated with incidence of small-for-gestational-age infants in fresh in vitro fertilization-intracytoplasmic sperm injection and embryo transfer cycles. Fertil Steril. 2020;113:745-52.

19. Zhang J, Liu H, Mao X, Chen Q, Si J, Fan Y, Xiao Y, Wang Y, Kuang Y. Effect of endometrial thickness on birthweight in frozen embryo transfer cycles: an analysis including 6181 singleton newborns. Hum Reprod. 2019;34:1707-15.

20. Zhang J, Du M, Sun L. Supraphysiological estradiol levels on the hCG trigger day are associated with SGA for singletons born from fresh embryo transfer. 2021:1-8.

21. Zhang J, Li Z, Sun L, Guan Y, Du M. Comparison of Pregnancy and Neonatal Outcomes of Single Frozen Blastocyst Transfer Between Letrozole-Induction and HRT Cycles in Patients With Abnormal Ovulation. Front Endocrinol (Lausanne). 2021;12:664072.

22. Zegers-Hochschild F, Adamson GD, Dyer S, Racowsky C, de Mouzon J, Sokol R, Rienzi L, Sunde A, Schmidt L, Cooke ID, et al. The International Glossary on Infertility and Fertility Care, 2017. Fertil Steril. 2017;108:393-406. 
23. Dai L, Deng C, Li Y, Zhu J, Mu Y, Deng Y, Mao M, Wang Y, Li Q, Ma S, et al. Birth weight reference percentiles for Chinese. PLoS One. 2014;9:e104779.

24. Gardner DK, Lane M, Schoolcraft WB. Physiology and culture of the human blastocyst. J Reprod Immunol. 2002;55:85-100.

25. Vander Borght M, Wyns C. Fertility and infertility: Definition and epidemiology. Clin Biochem. 2018;62:2-10.

26. Calhaz-Jorge C, De Geyter CH, Kupka MS, Wyns C, Mocanu E, Motrenko T, Scaravelli G, Smeenk J, Vidakovic S, Goossens V: Survey on ART and IUI: legislation, regulation, funding and registries in European countries: The European IVF-monitoring Consortium (EIM) for the European Society of Human Reproduction and Embryology (ESHRE). 2020, 2020:hoz044.

27. Qin JB, Sheng XQ, Wu D, Gao SY, You YP, Yang TB, Wang H. Worldwide prevalence of adverse pregnancy outcomes among singleton pregnancies after in vitro fertilization/intracytoplasmic sperm injection: a systematic review and meta-analysis. Arch Gynecol Obstet. 2017;295:285-301.

28. Cavoretto P, Candiani M, Giorgione V. Risk of spontaneous preterm birth in singleton pregnancies conceived after IVF/ICSI treatment: meta-analysis of cohort studies. 2018, 51:43-53.

29. Pinborg A, Wennerholm UB, Romundstad LB, Loft A, Aittomaki K, Soderstrom-Anttila V, Nygren KG, Hazekamp J, Bergh C. Why do singletons conceived after assisted reproduction technology have adverse perinatal outcome? Systematic review and metaanalysis. Hum Reprod Update. 2013;19:87-104.

30. Zhang J, Sun L, Li Z, Du M. HIGH SERUM ESTRADIOL LEVEL ON THE DAY OF HCG TRIGGER IS ASSOCIATED WITH SMALL FOR GESTATIONAL AGE INFANTS: A RETROSPECTIVE COHORT STUDY. Fertil Steril. 2018;110:E32-2.

31. Pereira N, Elias RT, Christos PJ, Petrini AC, Hancock K, Lekovich JP, Rosenwaks Z. Supraphysiologic estradiol is an independent predictor of low birth weight in full-term singletons born after fresh embryo transfer. Hum Reprod. 2017;32:1410-7.

32. Huang J, Lu X, Lin J, Chen Q, Gao H, Lyu Q, Cai R, Kuang Y. Association between peak serum estradiol level during controlled ovarian stimulation and neonatal birthweight in freeze-all cycles: a retrospective study of 8501 singleton live births. Hum Reprod. 2020;35:424-33.

33. Yang X, Zhang J, Wu J, Huang J, Chen Q, Lu X, Lyu Q, Kuang Y, Wang Y. Association between the number of oocytes retrieved and neonatal outcomes after freeze-all IVF cycles. Hum Reprod. 2019;34:1937-47.

34. Wang X, Du M, Guan Y, Wang B, Zhang J, Liu Z. Comparative neonatal outcomes in singleton births from blastocyst transfers or cleavage-stage embryo transfers: a systematic review and meta-analysis. Reprod Biol Endocrinol. 2017;15:36.

\section{Figures}




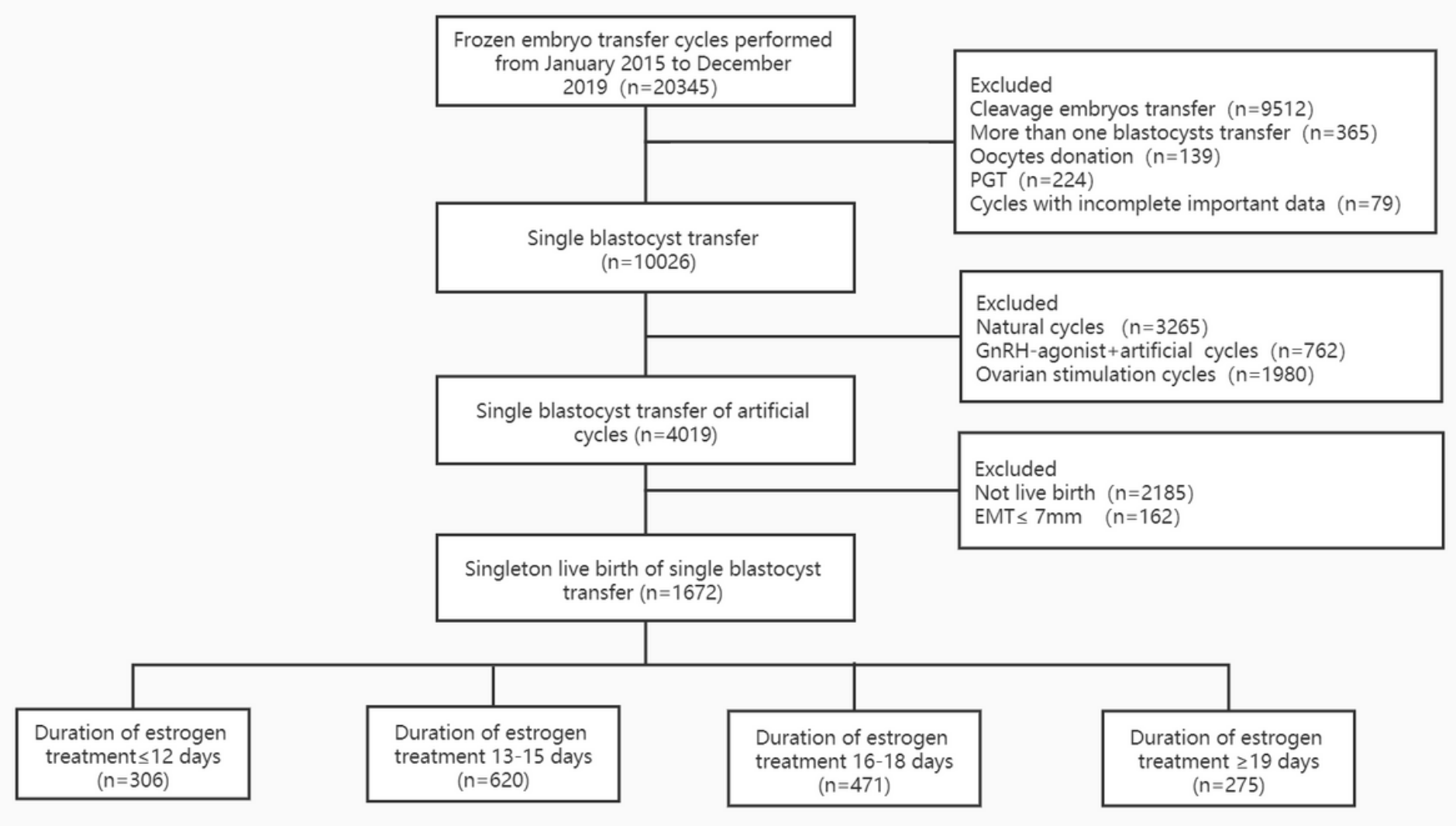

Figure 1

Flow chart of inclusion and exclusion criteria 